\title{
THICK-FILM NON-RECIPROCAL FERRITE ELEMENTS AND GUNN HYBRID OSCILLATORS IN MODIFIED THICK-FILM TECHNOLOGY
}

\author{
JANUSZ J. GONDEK, JAN KOPROWSKI and MAREK A. WOJCICKI \\ Department of Microelectronics, Institute of Electronics, ul. Czarnowiejska 78, 30-054 Krakow, \\ Poland
}

(Received August 1, 1982; in final form April 12, 1983)

In this paper are presented design and performance data on microwave Y-circulators and Gunn oscillators produced in thick-film technology. Y-circulators have been designed for central frequencies of 3,5 , and $10 \mathrm{GHz}$ with a satisfactory accuracy. New Polish made ferrite substrates, G-32, G-84 K, and G-175 have been used.

The Gunn oscillator was designed and corrected to the resonant frequencies 3,5 and $6 \mathrm{GHz}$ based on the integrated package diodes CXYP - 43 A and BXYP - 45 C (made in Poland). The results of the investigations are presented in tabular and graphical form.

\section{INTRODUCTION}

The trend towards miniaturization in the area of electronic circuits started on a world scale in the mid-fifties. It was a response to the need for small size electronic equipment with small weight and greater reliability, the production of which allowed for some savings in raw materials. This led to research on microwave in tegrated circuits, MIC.

In recent years integration has included microwave band circuits and has made possible the construction of practical small and medium power circuits, including those at millimetre waves. MICROWAVE INTEGRATED CIRCUITS are produced with the aid of MONOLITHIC and HYBRID technologies. In the frequency band up to $30 \mathrm{GHz}$ they are made exclusively using hybrid technology, most often using thin-film techniques. The great development of thick-film technology in recent years and its advantages over other techniques has made its use in MIC a possibility.

A team of specialists in microwave technology and microelectronics at the INSTITUTE OF ELECTRONICS AGH, the first in Poland, decided to investigate the possibility of making non-reciprocal ferrite elements and Gunn oscillators using thick-film technology.

The results of this research constitute the contents of the present paper.

\section{CONSTRUCTION AND TECHNOLOGY OF THE Y-CIRCULATOR}

One of the main problems of integrating microwave circuits in thick-film technology is the manufacture of non-reciprocal ferrite elements, circulators, insulators, phase-shifters, etc. The use of ferrite material as a substrate complicates certain operations in the thickfilm technological process, mainly the thick-film metallization.

However, considering the proved possibilities of MIC on dielectric substrates, ${ }^{2,6}$ it is helpful to use ferrite elements, since they increase the integrability of the entire circuit, mainly because of the small size. Also thanks to the low costs of production the technology can be used widely. It is necessary, however, to master new methods of designing microwave elements of this type, which would suit the specific character of the thick-film technology. 
First attempts to verify the method of designing microwave ferrite elements in thickfilm technology consisted in producing planar $Y$-circulators for centre frequencies, $f_{s}$, of 3.5 and $10 \mathrm{GHz}$. In order to do this, new Polish made ferrite substrates have been used, manufactured by Unitra-Polfer. The ferrite types have been classified as G-32, G-84SK, and G-175. The electrical properties of these ferrites are given in Table $\mathrm{I}^{8}$ The dimensions of the substrate plates were $50 \times 30 \times 1 \mathrm{~mm}$, and they were manufactured to a tolerance of $\pm 2 \mu \mathrm{m}$ thickness. The substrates were polished.

TABLE I

Properties of new polish made ferrite materials for use as substrates for MIC $^{8}$

\begin{tabular}{|c|c|c|c|c|}
\hline \multirow[t]{2}{*}{ Parameter } & \multirow[t]{2}{*}{ Units } & \multicolumn{3}{|c|}{ Type of ferrite substrate } \\
\hline & & G32 & G84SK & G175 \\
\hline Centre frequency $f_{s}$ & $\mathrm{GHz}$ & 3 & 5 & 10 \\
\hline Magnetization of saturatio & & & & \\
\hline $4 \pi \mathrm{M}_{\mathrm{S}}$ & $\mathrm{mT}$ & 32 & 80,4 & 171 \\
\hline $\begin{array}{l}\text { Relative dielectric } \\
\text { premeability/in band/ }\end{array}$ & - & $12,5 \pm 10 \% / \mathrm{L} /$ & $15,0 \pm 10 \% / \mathrm{X} /$ & $14,3 \pm 10 \%$ \\
\hline Resonance line width $\Delta \mathrm{H}$ & $\mathrm{kA} / \mathrm{m}$ & 4,0 & 7,68 & 4,64 \\
\hline Dielectric loss $\operatorname{tg} \delta \epsilon$ & - & $15.10^{-4}$ & $14,9 \cdot 10^{-4}$ & $15.10^{-4}$ \\
\hline Roughness $R_{a}$ & $\mu \mathrm{m}$ & 0,4 & 0,4 & 0,4 \\
\hline Curie temperature & ${ }^{\circ} \mathrm{K}$ & 393 & 533 & 558 \\
\hline Gyromagnetic coefficient & & & & \\
\hline $\mathrm{g}_{\text {sk }}$ & - & $2,02 \pm 1 \%$ & $2,03 \pm 1 \%$ & $2,02 \pm 1 \%$ \\
\hline
\end{tabular}

where: $g_{s k}=\frac{f s \cdot 10^{3}}{17.6 \mathrm{H}_{\mathrm{O}}}$

and $\mathrm{H}_{\mathrm{O}}$ - intrinsic resonance magnetic field $\mathrm{A} / \mathrm{m}$

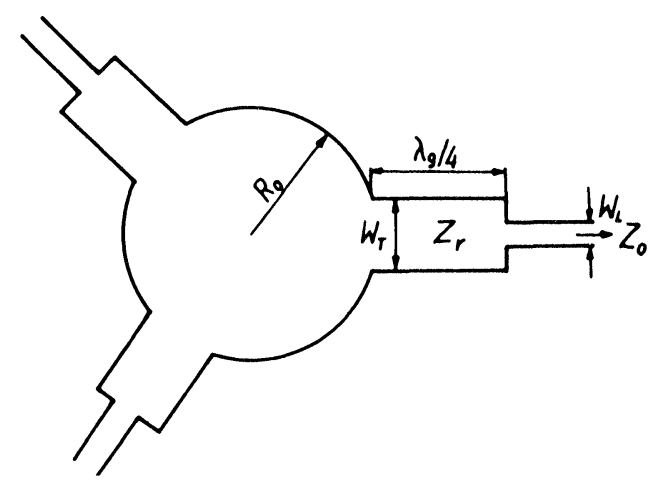

FIGURE 1 Planar construction of the designed Y-circulators. 
A microstrip Y-circulator in the planar version consists of two principal parts; a middle area of the resonator which consists of a circular region of metallization with a radius $R_{o}$ and three microstrip lines with a width $w_{L}$, arranged symmetrically every $120^{\circ}$. From the initial length, $1=\lambda_{g} / 4$, the microstrip lines may be somewhat widened to a width of $\mathrm{w}_{\mathrm{T}}$, thus giving quarterwave impedance transformers. Figure 1 shows a diagram of the planar construction of the Y-circulators.

\section{DESIGN BRIEF}

The parameters of the particular types of ferrite materials G-32, G-84SK and G-175 were evaluated in terms of assumed centre frequencies $f_{s}$, of 3,5 , and $10 \mathrm{GHz}$, using the criterion shown in equation 1.

$$
\begin{aligned}
10^{4} \pi \mathrm{M}_{\mathrm{s}} & \leqslant 0,5 \frac{4 \pi \mathrm{f}_{\mathrm{s}}}{\gamma} \\
\omega_{\mathrm{M}} & \leqslant 0,5 \omega_{\mathrm{s}}
\end{aligned}
$$

where:

$$
\gamma=\frac{2.8 \times 4 \pi}{10^{3}},\left(\frac{\mathrm{MHz} . \mathrm{m}}{\mathrm{A}}\right)
$$

and $\omega_{\mathrm{s}}=2 \pi \mathrm{f}_{\mathrm{s}}$ - radial centre frequency of circulation band,

$\omega_{M}=/ \gamma / 4 \pi M_{s}$ - wave frequency at which domain resonance of nagnetization takes place.

The metallization radius of the resonator was determined from the basic formula used for the construction of $\mathrm{Y}$-circulators, ${ }^{1}$ which can be written in a simplified version as:-

$$
R_{o}=\frac{87,8.10^{-3}}{f_{s} \sqrt{ } \epsilon_{r} \mu_{\text {eff. }}}
$$

where:

$$
\mu_{\mathrm{eff}} \sim 1-\left(\frac{\omega_{\mathrm{M}}}{\omega_{\mathrm{s}}}\right)^{2}
$$

The remaining parameters of the circulators were determined using the formulae given by Pucel (6) and Matthaei (5). The wave impedance of the microstrips $Z_{0}$, was assumed to be $50 \mathrm{Ohms}$. The computed geometric parameters of the circulators are given in Table II. 
TABLE II

Construction parameters of circulators

\begin{tabular}{|c|c|c|c|}
\hline $\begin{array}{l}\text { Dimensions in } \mathrm{mm} \\
\text { for circulators }\end{array}$ & & & \\
\hline with $\mathrm{f}_{\mathrm{s}}=$ & $3 \mathrm{GHz}$ & $5 \mathrm{GHz}$ & $10 \mathrm{GHz}$ \\
\hline on substrate & G 32 & G84SK & G 175 \\
\hline $\begin{array}{l}\text { Radius of resonator } \\
\mid \mathbf{R}_{\mathrm{O}} /\end{array}$ & 8,68 & 5,08 & 2,77 \\
\hline $\begin{array}{l}\text { Width of microstrip } \\
\qquad / w_{L} /\end{array}$ & 0.75 & 0.60 & 0.64 \\
\hline $\begin{array}{l}\text { Width of transformer } \\
\qquad / \mathrm{w}_{\mathrm{T}} /\end{array}$ & 2,50 & 1,15 & 0,95 \\
\hline $\begin{array}{l}\text { Length of transformer } \\
/ 1 /\end{array}$ & 7,20 & 4,02 & 2,07 \\
\hline
\end{tabular}

The metallizations of the circulators and the microstrips were printed using fine-line screens with Du Pont gold paste type 9791. The printed screens used were 400 mesh and masked indirectly. The metallization paste, type 9791, was fired according to the recommendations of the manufacturer ${ }^{7}$ using a peak temperature of $950^{\circ} \mathrm{C}$. The ground planes of the circulators were printed using Sprague type 62015 silver paste, fired at a peak temperature of $850^{\circ} \mathrm{C}$. After firing, both the circulators and the microstrips were inspected both visually and using a microscope.

\section{MEASUREMENTS ON CIRCULATORS}

Sample circulators were made in batches of 10 of each type. The electronic parameters of the circulators were measured in a specially designed jig in which the height of the permanent magnets could be adjusted. The permanent magnets, which were shielded to a diameter $2 \mathbf{R}_{\mathrm{o}}$, were used for polarizing the area of the resonator. Measurements were undertaken using a Hewlett-Packard jig, type HP-8410S. Standard connections in which the transmission losses between the microstrip and the co-linear connector had previously been measured, were used.

Table III gives the results of the measurements on the circulators. Two circulators of each type were measured, each with centre frequency, $f_{s}$, closest to the design frequency used. Such a table shows the repeatability of the manufacturing method using thick film technology.

TABLE III

Results of measurements of thick-film circulators

\begin{tabular}{ccccccc}
\hline $\begin{array}{l}\text { Specimen } \\
\text { no }\end{array}$ & $\mathrm{f}_{\mathrm{S}}$ & $\begin{array}{c}\mathrm{f}_{\mathbf{2}} \\
\mathrm{GHz}\end{array}$ & $\mathrm{f}_{\mathbf{1}}$ & $\begin{array}{c}\Delta \mathrm{f}= \\
\mathrm{f}_{\mathbf{1}}-\mathrm{f}_{2} \\
\mathrm{MHz}\end{array}$ & $\begin{array}{l}\text { Max. } \\
\text { isola- } \\
\text { tion }\end{array}$ & $\begin{array}{l}\text { Min. } \\
\text { inser- } \\
\text { tion }\end{array}$ \\
\hline 8 & 2,62 & 2,47 & 2,82 & 350 & 29,0 & 0,48 \\
5 & 2,67 & 2,56 & 2,91 & 410 & 28,7 & 0,53 \\
3 & 4,66 & 4,49 & 4,86 & 370 & 28,0 & 0,53 \\
2 & 4,67 & 4,51 & 4,79 & 280 & 27,8 & 0,51 \\
10 & 9,71 & 9,55 & 9,83 & 280 & 28,9 & 0,48 \\
4 & 9,72 & 9,55 & 9,85 & 300 & 29,9 & 0,50 \\
\hline
\end{tabular}




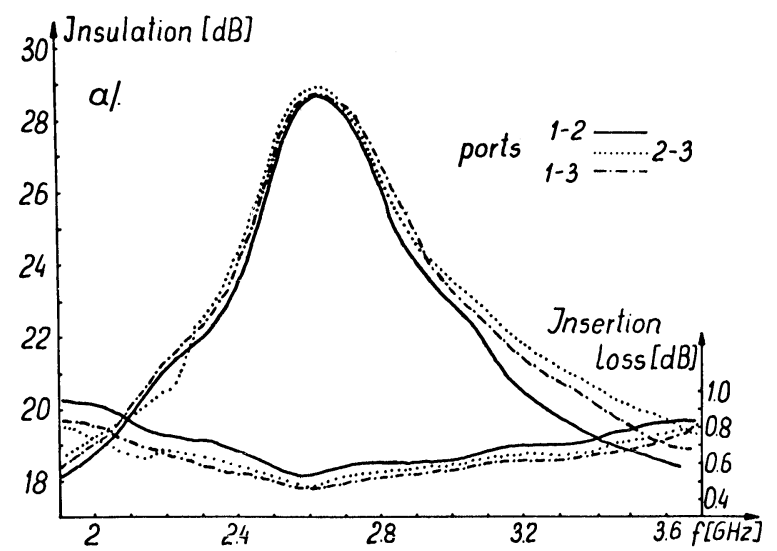

FIGURE 2a Insertion characteristics in the forward and return directions of the thick-film circulators $\mathrm{f}_{\mathrm{s}}=3 \mathrm{GHz}$.

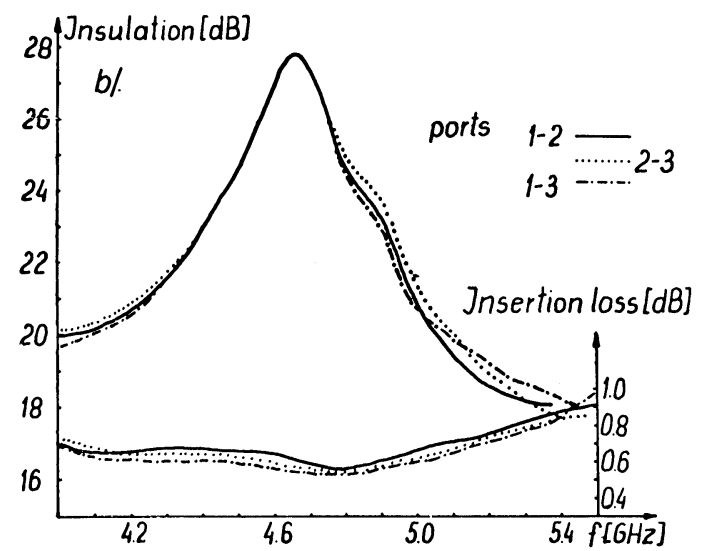

FIGURE 2b Insertion characteristics in the forward and return directions of the thick-film circulators $f_{\mathrm{S}}=5 \mathrm{GHz}$.

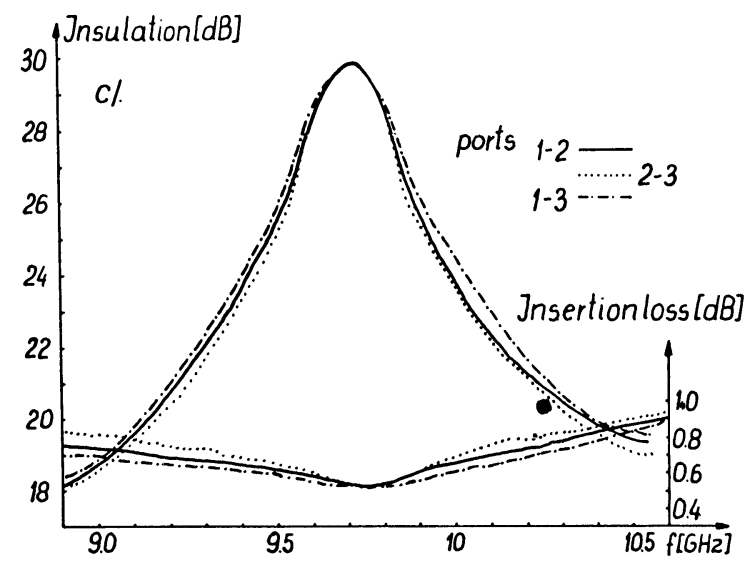

FIGURE 2c Insertion characteristics in the forward and return directions of the thick-film circulators $\mathrm{f}_{\mathrm{s}}=10 \mathrm{GHz}$. 
Figure 2 shows the insertion characteristics both in the forward and return directions/ of the thick film circulators for the three centre frequencies used. (Figure $2 \mathrm{a} \mathrm{f}_{\mathrm{s}}=3 \mathrm{GHz}$; Figure $2 \mathrm{~b}_{\mathrm{s}}=5 \mathrm{GHz}$; Figure $2 \mathrm{c} \mathrm{f}_{\mathrm{s}}=10 \mathrm{GHz}$.)

On analysing the results shown in Figure 2 one can observe the good repeatability and also the symmetry of the insertion characteristics both in the forward and return direction.

\section{DESIGN OF GUNN OSCILLATORS IN THICK-FILM TECHNOLOGY}

The major application of microwave systems and microwave devices is with the technique of transmitting information. A radio transmitter, satellite radio communication devices, radio-astronomy devices and radio-location devices of various kinds all use microwave systems and microwave devices. Miniature oscillating and amplifying systems are, therefore, very useful. One such oscillator is the oscillator based on the Gunn diode. This system was chosen by the authors to see if it was possible to realize Gunn oscillators using thick film technology. Usually, Gunn oscillators are made by direct connection of Gunn diodes - as are active elements - with microwave resonators. They can be tuned by changing the parameters of the Gunn diode by applying a polarising voltage. Modulation of the carrier frequency can also be affected in this way. Additional tuning can be affected by using a varactor diode. Gunn oscillators also contain coupling filters.

A Gunn oscillator consists of the following elements:-

a) A band pass filter, usually a basic microstrip resonator.

b) A Gunn diode.

c) A varactor diode for tuning to frequency.

d) Two low pass filters for supplying power.

e) A directional coupler for supplying the high frequency signal.

A simplified diagram of such an oscillator is given in Figure 3.

Other configurations of Gunn oscillators are possible and four versions are shown in Figure 4. (Figures 4a-d).

The oscillator shown in Figure 3 consisted of a band pass filter with parallel coupled half way resonators used as a resonator. In order to match the impedence of the resonator, the authors used two impedence transformers giving a so called convergent passage with a triangular distribution. For low pass filters planar realisation of a $1 / 2 \pi$ type filter was used. For the high frequency transformer a strip coupler made from ASL was used.

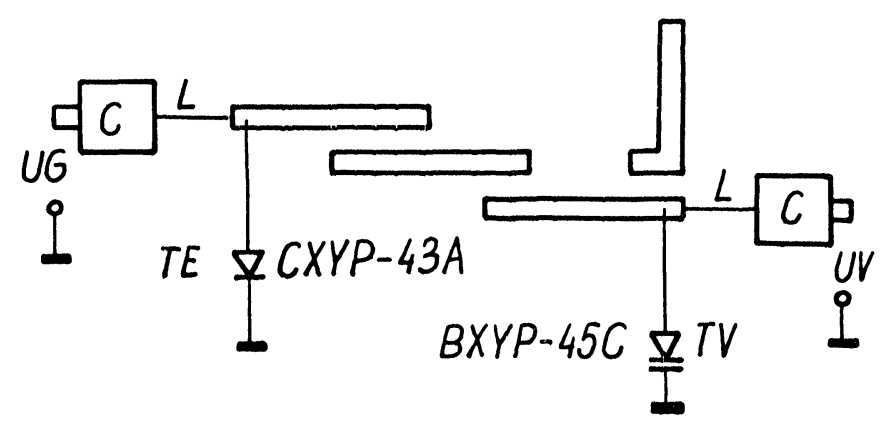

FIGURE 3 The designed Gunn oscillator. 

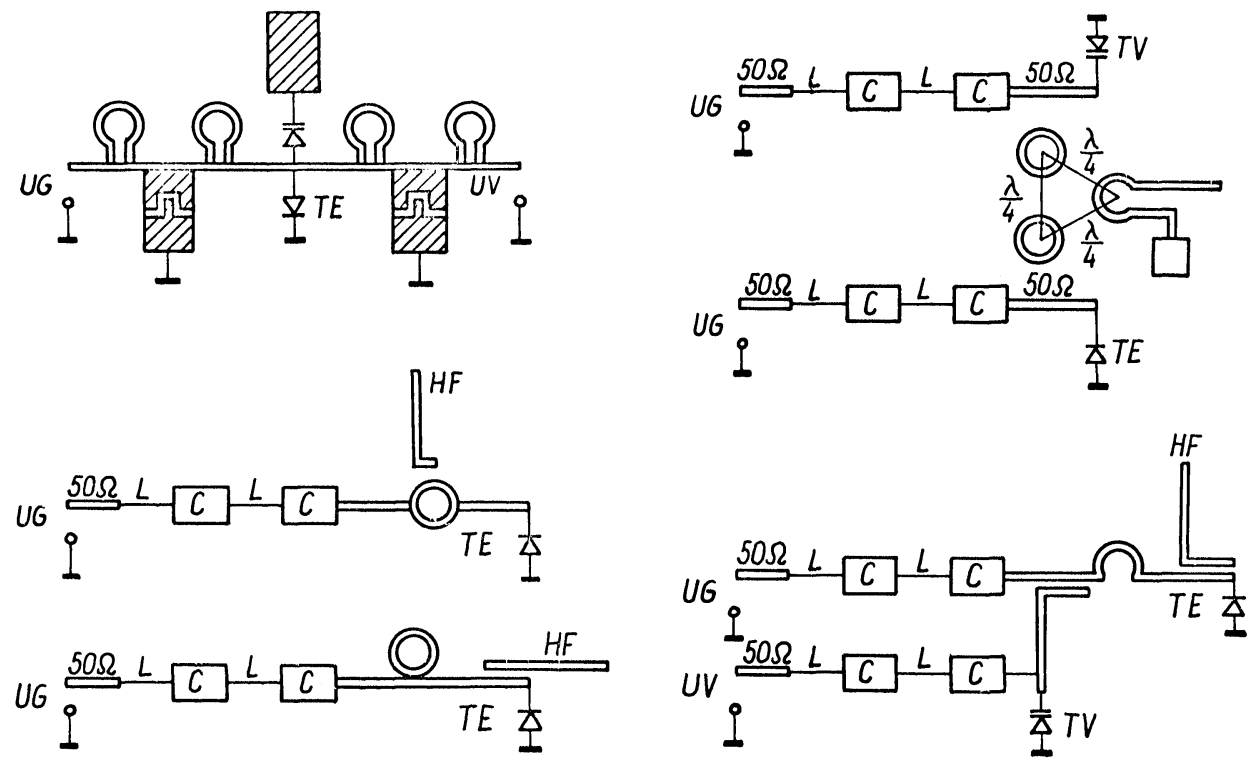

FIGURE 4 Examples of other configurations of Gunn oscillators.

The following design parameters were adopted

- centre frequency $F_{o}=5 \mathrm{GHz}$

- pass band $\mathrm{F}=2 \mathrm{GHz}$

- permissible changes in insertion loss in pass band $\mathrm{L}_{\mathrm{Ar}}=3 \mathrm{~dB}$

- input impedance $\mathrm{z}_{\text {in }}=50 \Omega$

- ASL impedance $\mathrm{z}_{\mathrm{o}}=50 \Omega$

- substrate: alumina ceramics with $\epsilon_{\mathrm{r}}=9.5$, dimensions $50 \times 30 \times 0.5 \mathrm{~mm}$.

In the design of the filter the method given by Matthaei ${ }^{5}$ was used. It was also possible to use asymmetrical lines (ASL) design programmes that had been prepared and which have been given in other papers. ${ }^{2-6}$ The following minimum values of coupling gaps were used; in the strip resonator, $200 \mu \mathrm{m}$, and in the directional coupler $50 \mu \mathrm{m}$.

\section{OSCILLATOR REALISATION}

For the production of the thick-film Gunn oscillators fine line screen printing was used, just as in the case of the circulators. The strip elements of the oscillator were printed using DP-9791 gold paste through a metallized nylon printing screen of 330 Mesh. The shields were printed using DP-9780 platinum silver pastes with a screen of mesh size 150 . Both of these pastes were prepared and fired according to the manufacturer's instructions. ${ }^{7}$

The coupling gap in the direction coupler was made using a laser beam system manufactured by Optronik, and the coupling gaps of the half-wave resonators were prepared using normal fine line printing techniques. The holes for the Gunn and varactor diodes were made in the ceramics by means of an ultrasonic spark machine type, UDA-3. The assembling of the diodes and the co-axial connections were made with the use of conductive glues based on organic resins. The Gunn diode was equipped with a special cooling system using distilled water. 


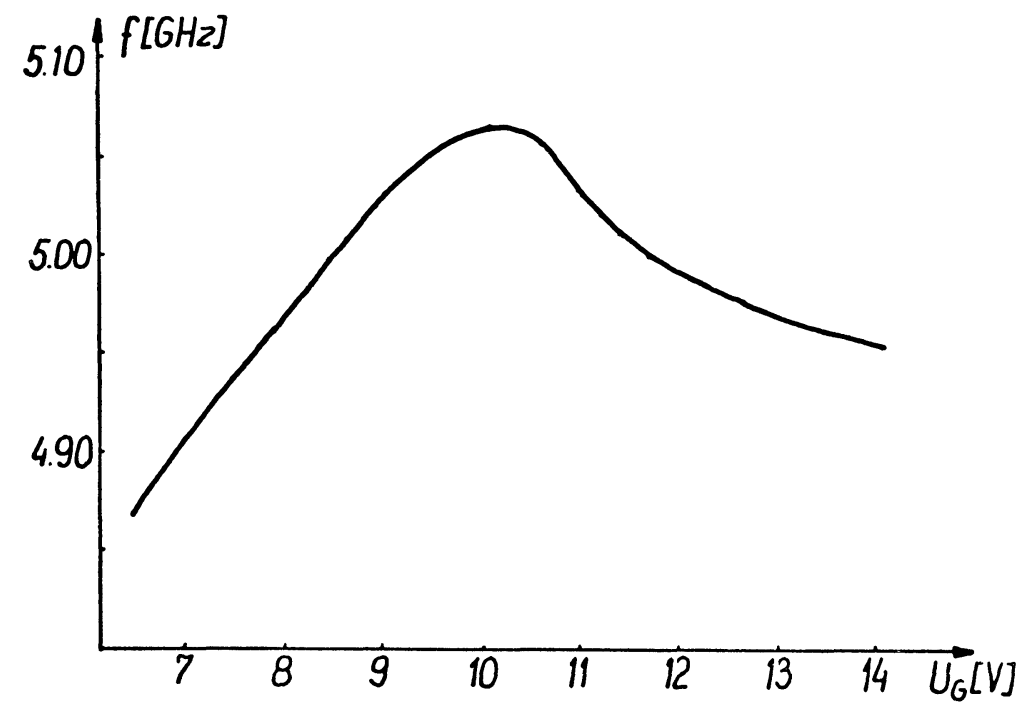

FIGURE 5 The characteristic $f_{g}$ vs $U_{G}$.

\section{MEASUREMENTS ON GUNN OSCILLATORS}

Measurements of the electrical parameters of the Gunn oscillators were made by a network analyser manufactured by Hewlett Packard HP-8410S. The samples were palced in a shielded enclosure to protect them from the influence of external electro magnetic fields.

Results of the measurements are shown in Figures 5,6 and 7. Figure 5 shows the relationship between the generated frequency, $f_{g}$, and the polarizing voltage on the Gunn

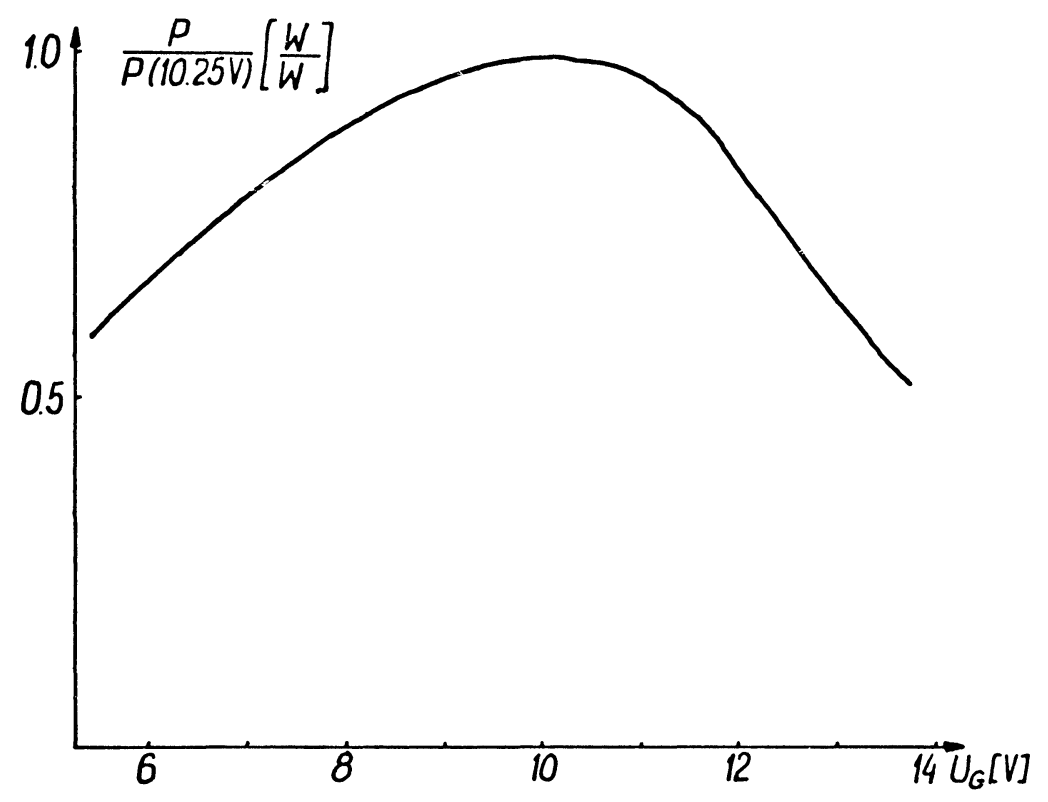

FIGURE 6 Relative change of power of the oscillator as a function of voltage $U_{G}$. 


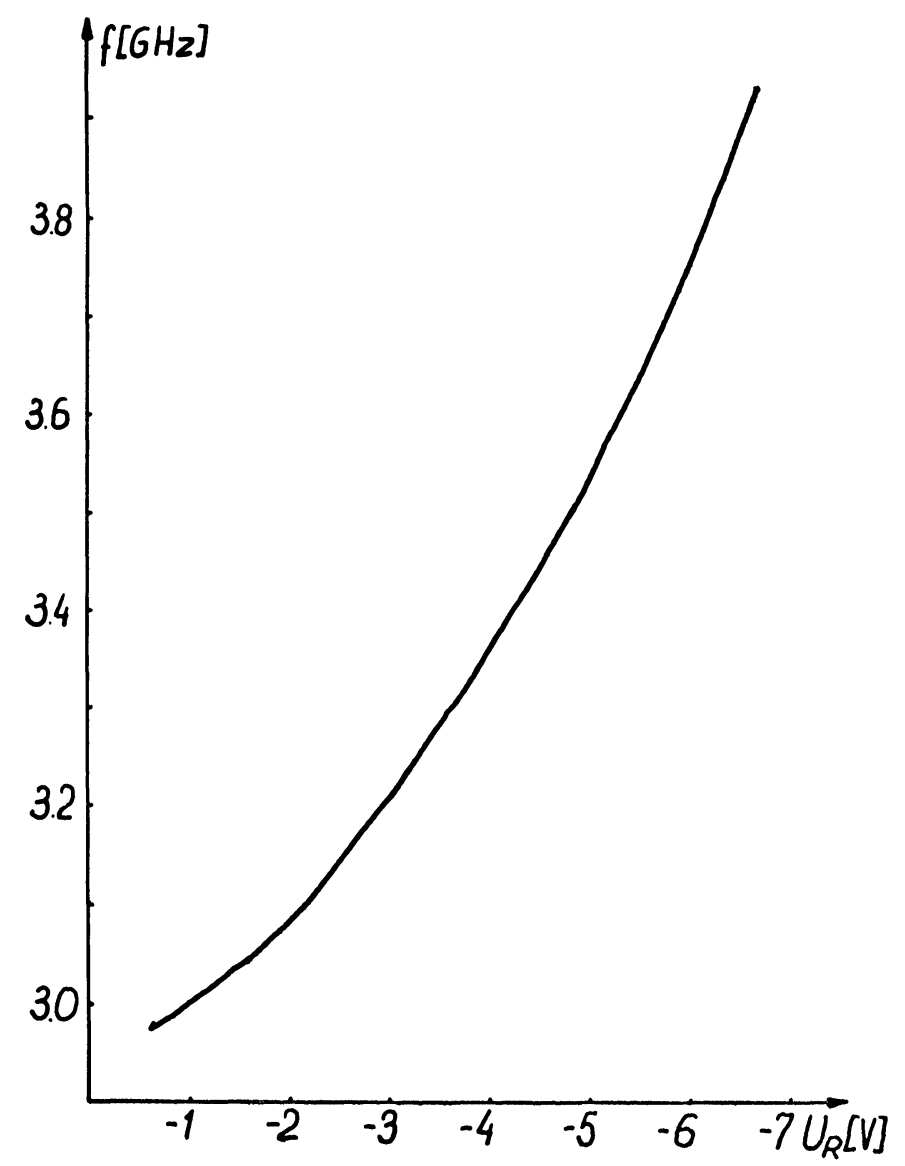

FIGURE 7 The characteristic $\mathrm{f}_{\mathrm{g}}$ vs $\mathrm{U}_{\mathrm{R}}$.

diode, $\mathrm{U}_{\mathrm{G}}$. Figure 6 shows the relationship obtained between the relative change of power. $P$, of the generator and the polarizing voltage on the Gunn diode, $U_{G}$. Figure 7 shows the relationship between the generated frequency, $f_{g}$, and the voltage supplied to the varactor diode, $\mathrm{U}_{\mathrm{R}}$.

The quality factor of the resonances obtained lay between $Q$ values of 156 and 208 . The tuning range of the oscillator, using the polarizing voltage on the Gunn diode $U_{G}$, was relatively small, only about $0.2 \mathrm{GHz}$. It was found that the resonant frequency could be shifted by about $1.3 \%$ due to slight variations in designs. It was also observed that oscillations were found in the 8 to $12 \mathrm{GHz}$ band which had an amplitude approximately $60 \%$ lower than that of the basic oscillations.

After connecting the varactor diode into the circuit, it was found that the generated frequency, $\mathrm{f}_{\mathrm{g}}$, decreased to a middle value of $3.5 \mathrm{GHz}$. In this way the possibility of tuning the oscillator over a broad range of frequencies was realized. (See Figure 7.)

\section{CONCLUSIONS}

The realization of non-reciprocal ferrite elements and oscillators using Gunn diodes in thick-film technology has shown that it is sensible to continue research in this direction, 
particularly with a view to constructing inexpensive and reliable microwave circuits. Work is therefore continuing on the possibility of the direct printing of thick film resistors on to ferrite substrates in order to design new types of isocirculators. It is hoped in the future that other types of microwave sub-assemblies will be prepared using thick-film technology, sub-assemblies such as phase-shifters, couplers and amplifiers.

\section{REFERENCES}

1. O. Sakala, "Cirkulatory pro mikrovolne obwody." Slaboproudy abzor. 38, 0-4, 174-181, Praga. (1977).

2. J.J. Gondek, M.A. Wójcicki, and J. Caber, Proceedings 31st Electronic Components Conference, Atlanta, USA (1981) 474-488.

3. J.J. Gondek, M.A. Wójcicki, and J. Koprowski, Electrocomponent Science and Technology, 9, pp. 157-163 (1981).

4. A. Jeleński, Mikrofalowa elektronika ciala stalego, PWN, Warszawa, (1976).

5. G.L. Matthaei, L. Young, and E.M. Jones, Microwave Filters, Impedance, Matching Networks and Coupling Structures. (McGraw-Hill Book Company, New York, 1964).

6. R.A. Pucel, and D.J. Masse, "Microstrip propagation on magnetic substrates. Part I - Design theory." IEEE Trans. Microwave Theory Techn., MTT-20, pp. 309-313, (1972).

7. Du Pont De Nemours Co. Inc., Thick-Film Materials. Electronic Materials Div., Wilmington, USA (1980).

8. Katalog materia $\tau \delta$ w firmy UNITRA-POLFER, Warszawa, (1980). 

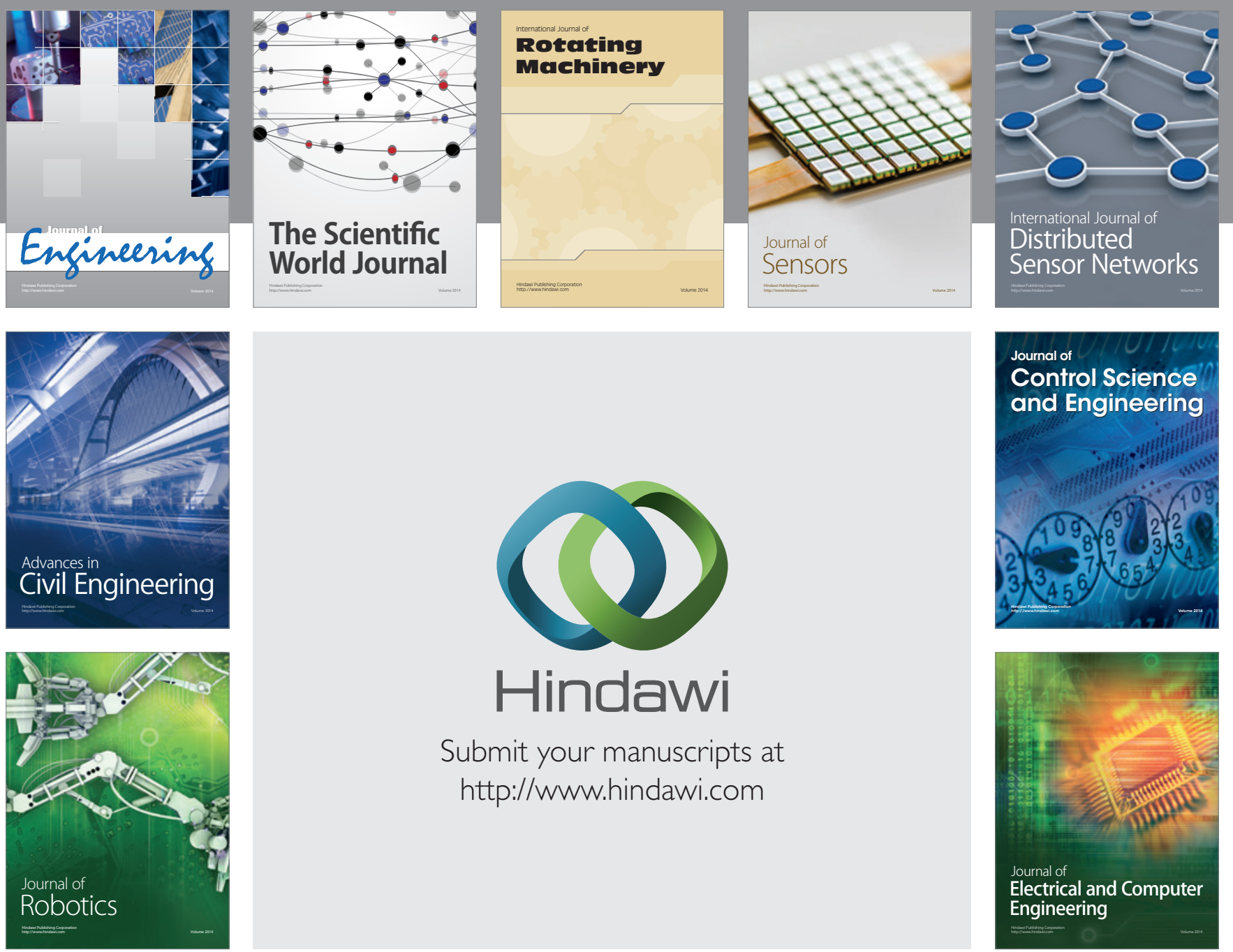

Submit your manuscripts at

http://www.hindawi.com
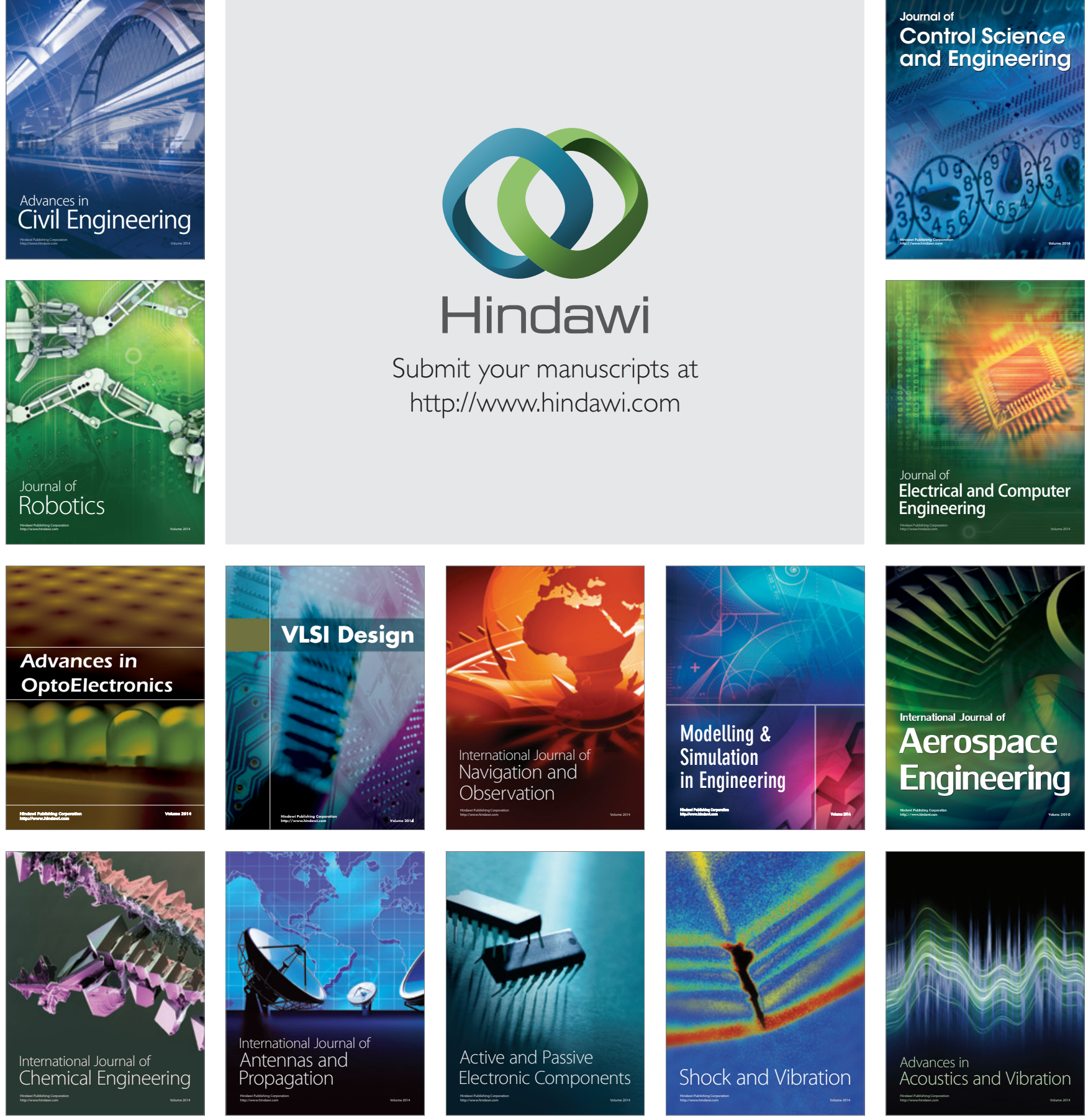